\title{
FORMAÇÃO DE PROFESSORES NO BRASIL: HISTÓRIA, POLÍTICAS E PERSPECTIVAS.
}

\author{
Maria Célia Borges \\ marcelbor@gmail.com \\ Universidade Federal do Triângulo Mineiro-UFTM \\ Orlando Fernández Aquino \\ ofaquino@gmail.com \\ Universidade Federal do Triângulo Mineiro-UFTM/Universidade de Uberaba-Uniube \\ Roberto Valdés Puentes \\ robertopuentes@faced.ufu.br \\ Universidade Federal do Uberlândia-UFU
}

RESUMO:

Propôs-se, neste texto, discutir o tema da formação docente contemplando aspectos históricos, políticos e teóricos. Na primeira parte introduz-se o enfoque histórico, examinando a trajetória da formação de professores no Brasil, desdobrando-se em seis períodos que se iniciam com a aprovação da Lei das Escolas de Primeiras Letras, em 1827. Nota-se que a formação de professores em cursos específicos foi inaugurada no Brasil no final do século XIX com Escolas Normais destinadas à formação de docentes para as "primeiras letras". A discussão segue e culmina com a promulgação da Lei de Diretrizes e Bases da Educação (LDB), em 1996; em seguida, discute-se sobre as políticas educacionais expressas na legislação, antes e após a LDB 9.394/1996, as Diretrizes Curriculares Nacionais (2002) e a Política Nacional de Formação de Professores, editada por meio do Decreto Presidencial n. ${ }^{\circ}$ 6.755/2009. Verificase que as políticas e a práticas do sistema educacional brasileiro encontram-se orientadas pelos valores do neoliberalismo e, por isso, apresentam contradições. Por fim, na história brasileira, as políticas sobre formação de professores evidenciam sucessivas mudanças e reformas, contudo ainda não estabeleceram um padrão consistente de preparação docente para resolver os problemas enfrentados pela educação escolar.

Palavras-chave: Formação de Professores. História e políticas de formação. Perspectivas da formação docente.

\section{TEACHERS' CONTINUING STUDIES IN BRAZIL: HISTORY, POLICIES AND PERSPECTIVES.}

ABSTRACT:

This paper proposes a discussion on the teachers' continuing studies approaching historical, political and theoretical aspects. Firstly we present the historical focus, examining teachers' continuing studies in Brazil that are divided in six periods beginning with the approval of Law of First Letters Schools in 1827. It can be observed that teachers' continuing studies in specific courses were introduced in Brazil in the late nineteenth century with 'Escolas Normais' designed to the teachers' continuing studies of "the first letters". Following the discussion 
culminates in the promulgation of Law of Guidelines and Bases of Education in 1996; in the sequence we discuss on the educational policies expressed on the legislation, before and after Law 9,394/1996, the National Curriculum Guidelines (2002) and the National Policy of Teachers' continuing studies, put in place by Presidential Decree \# 6,755/2009. Analyzing the policies and practices of the Brazilian educational system we can erify that they are guided by neoliberalism values and due to this fact some contradictions are often shown. Finally, in Brazilian schools, the formative policies evidence successive changes, although they still have not established a consistent pattern of teaching preparation for solving problems faced by school education.

Keywords: Teachers' continuing studies; History and formation policies; perspectives on teachers' continuing studies.

\section{Introdução}

O problema da formação de professores é antigo e, ao mesmo tempo, atual e as pesquisas mostram a necessidade da continuidade de investigações na área, bem como da busca de políticas educacionais e de práticas consistentes para amenizar os problemas hodiernos.

Destarte, o objetivo deste texto é discutir o tema da formação de professores, contemplando os aspectos históricos, políticos e teóricos. Como procedimentos metodológicos, utilizou-se a pesquisa bibliográfica, recorrendo à revisão da literatura atual, baseada em Gatti e Barreto, Severino, Saviani, Luckesi, dentre outros. O texto está assim estruturado: na primeira parte introduz-se o enfoque histórico, examinando a trajetória da formação de professores no Brasil, desdobrando-se em seis períodos que se iniciam com a aprovação da Lei das Escolas de Primeiras Letras, em 1827, e culminam com a promulgação da Lei de Diretrizes e Bases da Educação (LDB), em 1996; em seguida, discute-se sobre as políticas educacionais expressas na legislação, antes e após a LDB 9.394/1996, as Diretrizes Curriculares Nacionais (2002) e a Política Nacional de Formação de Professores, editada por meio do Decreto Presidencial n. ${ }^{\circ}$ 6.755/2009. Por fim, analisam-se, criticamente, as políticas educacionais, tecendo ponderações críticas e vislumbrando perspectivas.

\section{A história da formação dos professores no Brasil}

Em nível global, a necessidade de formação docente fora preconizada por Comenius, no século XVII, sendo que o Seminário dos Mestres, instituído por São João Batista de La Salle em 1684, foi o primeiro estabelecimento de ensino destinado à formação de professores. Mas, somente após a Revolução Francesa, mais precisamente no final do século XVIII, iniciou-se o processo de valorização da instrução escolar, período em que foram criadas as Escolas Normais com a finalidade de formar professores. Assim, nasceu a necessidade de universalizar a instrução elementar e, para tanto, a urgência de organização dos sistemas nacionais de ensino. Na visão de Saviani (2009), foi a partir daí que se introduziu a distinção entre Escola Normal Superior para formar professores de nível secundário e a Escola Normal simplesmente, também chamada de Escola Normal Primária, para preparar professores do ensino primário. 
Dessa forma, a primeira instituição denominada Escola Normal foi proposta pela convenção, em 1794 e instalada em Paris em 1795. Em sequência, os países como França, Itália, Alemanha, Inglaterra e Estados Unidos foram instalando, ao longo do século XIX, suas Escolas Normais.

No Brasil, a preocupação com o preparo de professores não é recente, pois, já em 1882, Rui Barbosa fez uma análise da educação imperial e criticou a situação em que se encontrava o ensino superior brasileiro, especialmente no Direito. Em um parecer de 1882, explicitava a carência de "[...] uma reforma completa dos métodos e dos mestres." (RIBEIRO JÚNIOR, 2001, p. 29). Contudo, no Brasil, tal preocupação surge de forma explícita após a independência, quando se discutiu a abertura e a organização da instrução popular. Saviani (2009, p.143), ao examinar as questões pedagógicas em articulação com as transformações que se processam na sociedade brasileira ao longo dos últimos dois séculos, dividiu em seis períodos a história de formação de professores no Brasil:

1. Ensaios intermitentes de formação de professores (1827-1890). Esse período se iniciou com o dispositivo da Lei das Escolas de Primeiras Letras, que obrigava os professores a se instruírem no método do ensino mútuo, às próprias expensas; estendeu-se até 1890, quando prevaleceu o modelo das Escolas Normais.

2. Estabelecimento e expansão do padrão das Escolas Normais (18901932), cujo marco inicial foi a reforma paulista da Escola Normal, tendo como anexo a escola-modelo.

3. Organização dos Institutos de Educação (1932-1939), cujos marcos foram as reformas de Anísio Teixeira no Distrito Federal, em 1932, e de Fernando de Azevedo em São Paulo, em 1933.

4. Organização e implantação dos Cursos de Pedagogia e de Licenciatura e consolidação do modelo das Escolas Normais (1939-1971).

5. Substituição da Escola Normal pela Habilitação Específica de Magistério (1971-1996).

6. Advento dos Institutos Superiores de Educação, Escolas Normais Superiores e o novo perfil do Curso de Pedagogia (1996-2006).

O primeiro período, denominado por Saviani (2009) "Ensaios intermitentes de formação de professores (1827-1890)", localizou-se durante todo o período colonial, com início nos colégios jesuítas, passando pelas aulas régias, implantadas pelas reformas pombalinas, até os cursos superiores, criados a partir de Dom João VI, em 1808; tempo em que não se manifestou claramente a preocupação com a formação de professores. Tal preocupação só apareceu em 15 de outubro de 1827, quando foi promulgada a Lei das Escolas das Primeiras Letras. No artigo $4^{\circ}$ da Lei, ao determinar o método mútuo, determinou-se que os professores devessem ser treinados para o uso do método, às próprias custas, nas capitais das Províncias. Vê-se que a formação de professores, até então, não contava com investimento do Governo; o que é compreensível numa sociedade em que a educação ainda era privilégio de poucos e direcionada a uma pequena elite.

A instrução primária foi colocada sob a responsabilidade das Províncias somente após a promulgação do Ato Adicional de 1834. Elas tinham que adotar, para a formação dos professores, o modelo dos países europeus, na criação das Escolas Normais. Assim, segundo Saviani (2009), foram criadas Escolas Normais nas diversas Províncias, na seguinte ordem: 
Bahia (1836); Mato Grosso (1842); São Paulo (1846); Piauí (1864); Rio Grande do Sul (1869); Paraná e Sergipe (1870); Espírito Santo e Rio Grande do Norte (1873); Paraíba (1879); Rio de Janeiro (DF) e Santa Catarina (1880); Goiás (1884); Ceará (1885); Maranhão (1890). Essas escolas eram abertas, fechadas e reabertas periodicamente, tendo existências intermitentes.

No início, as Escolas Normais preconizavam uma formação específica, guiando-se pelas coordenadas pedagógico-didáticas. Entretanto, contrariamente a essa expectativa,

[...] predominou nelas a preocupação com o domínio dos conhecimentos a serem transmitidos nas escolas de primeiras letras. O currículo dessas escolas era constituído pelas mesmas matérias ensinadas nas escolas de primeiras letras. Portanto, o que se pressupunha era que os professores deveriam ter o domínio daqueles conteúdos que lhes caberia transmitir às crianças, desconsiderando-se o preparo didático-pedagógico. (SAVIANI, 2009, p.144)

O segundo período foi denominado "Estabelecimento e expansão do padrão das Escolas Normais (1890-1932)”, cujo marco inicial foi a reforma paulista da Escola Normal, tendo como anexo a escola modelo.

A reforma da instrução pública do Estado de São Paulo (1890) definiu o modelo de organização e funcionamento das Escolas Normais. Saviani (2009) destaca que na visão dos reformadores, "[...] sem professores bem preparados, praticamente instruídos nos modernos processos pedagógicos e com cabedal científico adequado às necessidades da vida atual, o ensino não pode ser regenerado e eficaz”. (São Paulo, 1890). Dessa forma, só poderão sair de escolas normais organizadas em condições de insuficiência do seu programa de estudo e de carência de preparo dos seus alunos. Portanto, era importante, naquele momento, reformar o plano de estudos.

A partir daí, a escola foi reformada, preconizando o enriquecimento dos conteúdos curriculares anteriores e, ao mesmo tempo, com ênfase nos exercícios práticos de ensino, corporificada pela criação da escola - modelo anexa à Escola Normal - sendo a principal inovação da reforma. Os custos de instalação também foram assumidos pelos reformadores.

Gatti e Barretto (2009) confirmam a ideia de que a formação de professores em cursos específicos foi inaugurada no Brasil, no final do século XIX, com Escolas Normais destinadas à formação de docentes para as "primeiras letras". "Essas escolas correspondiam ao nível secundário de então. Devemos lembrar que, nesse período, e ainda por décadas, a oferta de escolarização era bem escassa no país, destinada a bem poucos". (GATTI; BARRETTO, 2009, p. 37).

Nesse prisma, entenderam que o preparo dos novos professores exigia a organização curricular, com preparação dos conteúdos científicos e também a preparação didáticopedagógica, para garantir, de fato, professores bem formados. Nesse modelo, o padrão de Escola Normal tendeu a se firmar e se expandir em todo o país. Porém, o padrão da Escola Normal teve seu ímpeto reformador enfraquecido após a primeira década, prevalecendo a preocupação com o domínio dos conhecimentos a serem transmitidos.

No contexto histórico, vê-se que as primeiras décadas do século XX caracterizaram-se pelo debate das ideias liberais, sobre cuja base se advogou a extensão universal, por meio do 
Estado, do processo de escolarização, considerado o grande instrumento de participação política. Na visão de Saviani (2007),

É, pois, a ideia central da vertente leiga da concepção tradicional, isto é, a transformação, pela escola, dos indivíduos ignorantes em cidadãos esclarecidos, que esteve na base do movimento denominado por Nagle (1974) de "entusiasmo pela educação", o qual atingiu seu ponto culminante na efervescente década de 1920. Mas é nessa mesma década que a versão tradicional da pedagogia liberal foi suplantada pela vertente moderna. (p.177)

Com a propagação das ideias modernas sobre a educação, criou-se, em 1924, a Associação Brasileira de Educação (ABE), com objetivo de congregar todas as pessoas, de várias tendências, em torno da bandeira da educação. Foi um espaço propício para a reunião de pessoas que se tornavam adeptas das novas ideias pedagógicas. Evoluiu tanto que, em 1927, a ABE organizou a I Conferência Nacional de Educação, evento que passou a ser promovido continuamente nos anos seguintes.

No terceiro período foi marcado pela "Organização dos Institutos de Educação (19321939)", cujos destaques são as reformas de Anísio Teixeira no Distrito Federal, em 1932, e de Fernando de Azevedo em São Paulo, em 1933.

Os Institutos de Educação representaram uma fase nova e foram concebidos como espaços de cultivo da educação, compreendidos não somente como objetos de ensino, mas também de pesquisa. As duas primeiras iniciativas tiveram a inspiração no ideário da Escola Nova. O Instituto de Educação do Distrito Federal foi concebido e implantado por Anísio Teixeira, em 1932, e dirigido por Lourenço Filho, o Instituto de Educação de São Paulo, implantado em 1933, por Fernando de Azevedo. (SAVIANI, 2009)

Pelo Decreto 3.810, de 19 de março de 1932, Anísio Teixeira procurou reorganizar as Escolas Normais, contemplando a cultura geral e a cultura profissional. Assim, os Institutos de Educação procuraram incorporar as exigências da pedagogia, que buscava se firmar como um conhecimento de caráter científico, caminhando para a consolidação de um modelo pedagógico-didático, de formação docente, corrigindo as ineficiências e distorções das tradicionais Escolas Normais do passado.

A preocupação em formar professores para o secundário, apareceu no início do século XIX, o que corresponde hoje aos atuais anos finais do Ensino Fundamental e ao Ensino Médio, em cursos regulares e específicos. Fez-se necessária a criação da Universidade para a formação desse profissional docente, pois, até então, o ofício era comumente exercido por profissionais liberais ou autodidatas. Há de se considerar, ainda, que o número de escolas secundárias, nessa época, era bem pequeno, bem como o número de alunos. A industrialização no país trouxe a necessidade de maior escolarização e, consequentemente, a expansão do sistema de ensino. O aumento da demanda de professores apareceu como uma consequência natural.

Gadotti (1999) traz, em seu livro, um esboço a partir do Manifesto dos Pioneiros (1932), que explicita a proposta da escola novista. Nesse sentido, propõe a criação da Universidade com a tríplice função de criar a ciência, transmiti-la e vulgarizá-la. Destaca a formação de professores para escolas primárias, secundárias, profissionais e superiores, com unidade na preparação do pessoal do ensino. Essas ideias foram consideradas inovadoras 
para a época, mas não conseguiram, na prática, avançar além da orientação da tendência liberal renovada progressivista ${ }^{1}$.

Como se sabe, na aplicação do ideário da escola novista, não se efetivou, uma vez que não havia condições objetivas, no interior da escola, para viabilizá-la (professores preparados, recursos didático-pedagógicos etc.) além de se chocar com as ideias vivas e atuantes da prática pedagógica tradicional. A ideologia que orientava a educação da época, sendo liberal, reafirmava a manutenção do capitalismo e não considerava as influências do contexto sóciopolitico-econômico na vida das pessoas, difundindo os valores de um darwinismo social ${ }^{2}$. Nesse prisma, o sistema escolar continuou seletivo e excludente. (LUCKESI, 2005)

Ao avançar na história, chega-se ao quarto período, o qual se caracterizou pela "Organização e implantação dos cursos de Pedagogia e de Licenciatura e consolidação no padrão das Escolas Normais (1939-1971)”. Os Institutos de Educação do Distrito Federal e de São Paulo foram elevados ao nível universitário, tornando-se a base dos estudos superiores de educação: o paulista incorporado à Universidade de São Paulo fundada em 1934, e o carioca à Universidade do Distrito Federal, criada em 1935.

A partir do Decreto 1.190, de 4 de abril de 1939, deu-se a organização definitiva da Faculdade Nacional de Filosofia da Universidade do Brasil e dos cursos de formação de professores para as escolas secundárias. Resultou-se, da orientação desse decreto, o "esquema $3+1$ ", adotado nos cursos de Licenciatura e Pedagogia. Os primeiros formavam professores para as diversas disciplinas dos currículos das escolas secundárias; os segundos formavam professores para exercer a docência nas Escolas Normais. Pelo esquema " $3+1$ ", três anos eram dedicados ao estudo das disciplinas específicas ou conteúdos cognitivos e um ano, para a formação didática. Salienta-se que, dessa forma, o modelo de formação de professores em nível superior perdeu a referência de origem, cujo suporte eram as escolas experimentais às quais competia fornecer uma base de pesquisa e dar caráter cientifico aos processos formativos.

Esse modelo (3+1), segundo conclusões de Gatti e Barreto (2009) fora aplicado também no Curso de Pedagogia, regulamentado em 1939, destinado a formar bacharéis especialistas em educação e, complementarmente, formar professores para as escolas normais, os quais poderiam, por extensão e portaria ministerial, lecionar algumas disciplinas no ensino secundário.

O Decreto Lei n. 8.530, de 2 de janeiro de 1946, conhecido como Lei Orgânica do Ensino Normal (BRASIL, 1946), trouxe a nova estrutura do Ensino Normal, que foi dividida em dois ciclos: o primeiro correspondia ao ciclo ginasial do curso secundário e tinha duração de quatro anos. Seu objetivo correspondia ao ciclo ginasial do curso secundário em Escolas Normais regionais. O segundo Ciclo, com a duração de três anos, correspondia ao ciclo colegial do curso secundário, com objetivo de formar regentes do ensino primário e funcionamento nas Escolas Normais e nos Institutos de Educação.

Se, por um lado, os cursos normais de primeiro ciclo, pela similitude aos ginásios, possuíam currículos centrados nas disciplinas de cultura geral, no estilo das velhas Escolas Normais, tão criticadas; por outro, os cursos de segundo ciclo contemplavam todos os fundamentos introduzidos pelas reformas da década de 1930. Saviani (2009) afirmou que foi criada uma situação dualista, uma vez que os cursos de Licenciatura centraram-se nos conteúdos-cognitivos, em detrimento do aspecto pedagógico-didático tratado como um apêndice de menor importância, representado pelo curso de didática, encarado como uma 
simples obrigação formal para atender a exigência para obtenção do registro profissional de professor. Nesse sentido, também o Curso de Pedagogia,

[...] à semelhança do que ocorreu com os cursos normais, foi marcado por uma tensão entre os dois modelos. Embora seu objeto próprio estivesse todo ele embebido do caráter pedagógico-didático, este tendeu a ser interpretado como um conteúdo a ser transmitido aos alunos antes que como algo a ser assimilado teórica e praticamente para assegurar a eficácia qualitativa da ação docente. Consequentemente, o aspecto pedagógico-didático, em lugar de se constituir em um novo modelo a impregnar todo o processo da formação docente, foi incorporado sob a égide do modelo dos conteúdos culturaiscognitivos. (SAVIANI, 2009, p.147)

Vale lembrar que, em 1968, o Congresso Nacional aprovou a Reforma Universitária ${ }^{3}$, pela Lei $\mathrm{n}^{\circ} 5.540$, de 28/11/68, definindo normas de organização e funcionamento do ensino superior. $\mathrm{O}$ período ditatorial brasileiro ficou marcado por fortes ajustes em suas estruturas, por intermédio de leis que confirmaram o aparato coercitivo ao Estado, legitimando seu poder e autoritarismo por meio da sobreposição do poder Executivo ao Legislativo; o que resultou, na educação, especialmente o ensino superior, em várias mudanças, em prol da manutenção da ordem conturbada pela crise educacional no plano interno.

Nesse período e no seguinte, a educação sofreu fortes influências da tendência liberal tecnicista, cuja ideologia era/é formar técnicos profissionais, de forma rápida, para atender ao mercado de trabalho. Nesse sentido, o objetivo central era o de adequar o sistema educacional à orientação política e econômica do regime militar: inserir a escola nos modelos de racionalização do sistema de produção capitalista. (LUCKESI, 2005).

Se, por um lado, evidenciam-se avanços com relação aos discursos; por outro, o sistema educacional continuou/continua excludente e dual, oferecendo um ensino propedêutico que, destinado à elite, prepara para a Universidade; e o ensino profissionalizante destinado à classe desprovida de riquezas.

O quinto período foi caracterizado pela "Substituição da Escola Normal pela Habilitação Específica de Magistério (1971-1996)”. As exigências para adequações no campo curricular foram desencadeadas pelo golpe militar de 1964, concretizadas mediante mudanças na legislação do ensino. A Lei 5.692/71 (Brasil 1971) modificou os ensinos primário e médio, introduzindo a denominação de Primeiro e Segundo Graus. Na nova estrutura, desapareceram as Escolas Normais, sendo instituída a habilitação específica de $2^{\circ}$ grau para o exercício do magistério de $1^{\circ}$ grau. O Parecer n. 349/72 (Brasil-MEC, 1972), aprovado em 6 de abril de 1972, organizou a Habilitação do Magistério em duas modalidades básicas: uma com a duração de três anos (2.200 horas), que habilitaria a lecionar até a $4^{\mathrm{a}}$. Série; e outra com a duração de quatro anos (2.900 horas), habilitando ao magistério até a $6^{\mathrm{a}}$. Serie do $1^{\mathrm{o}}$ grau. Desse modo, o currículo mínimo compreendia o núcleo comum, obrigatório em todo o território nacional, para todo o ensino de $1^{\circ}$ e $2^{\circ}$ graus, destinado a garantir a formação geral; e uma parte diversificada, visando à formação especial. O Curso Normal antigo cedeu lugar a uma Habilitação de $2^{\circ}$ grau. A formação de professores para o antigo ensino primário foi, assim, reduzida a uma habilitação dispersa em meio a tantas outras, configurando-se um quadro de precariedade preocupante. 
Em 1982, para atenuar a gravidade do problema, o Governo criou o projeto Centros de Formação e Aperfeiçoamento do Magistério (CEFAMs), com objetivo de revitalização da Escola Normal. Contudo, o projeto teve abrangência e aproveitamento restritos. (SAVIANI, 2009)

A Lei 5.692/71 previu a formação dos professores para as quatro últimas séries do ensino de $1^{\circ}$ Grau e, para o Ensino de $2^{\circ} \mathrm{Grau}$, em cursos de Licenciatura curta (3 anos de duração) ou plena (4 anos de duração). Para o Curso de Pedagogia, além da formação de professores para Habilitação Específica de Magistério, recebeu a atribuição de formar os especialistas em Educação, diversificados em diretores de escola, orientadores educacionais, supervisores escolares e inspetores de ensino.

A partir de 1980, surgiu um movimento pela reformulação do Curso de Pedagogia e Licenciatura, que adotou o princípio da "docência como base da identidade profissional de todos os profissionais da educação" (SILVA, 2003, P. 68 e 79).

Esse período sofreu também influências das ideias da Pedagogia Progressista Libertadora ${ }^{4}$, de Paulo Freire, com resquícios, ainda, da opressão da ditadura militar.

Na visão de Freitas (2002) há um aspecto significativo nesse período, uma vez que, nos anos 80, acontece uma ruptura com o pensamento tecnicista que se impunha na área de educação, até aquele momento. Nesse prisma, diversos educadores produziram e explicitaram concepções avançadas sobre a formação docente, destacando o caráter sócio histórico da formação, a necessidade de um profissional com formação ampla, com pleno domínio e compreensão da realidade de seu tempo, desenvolvimento da consciência crítica que lhe permita interferir nas condições da escola, da educação, da sociedade e transformá-las.. Essa concepção emancipadora de educação e de formação avançou na superação de dicotomias entre a ideia de professores e especialistas, pedagogia e licenciaturas, especialistas e generalistas, uma vez que a escola avançava na democratização de seus espaços, possibilitava revisão das relações de poder e trabalhava para construção de novos projetos coletivos. Essa construção teórica avançou no sentido de construção de uma nova concepção de profissional da educação que tem na docência e no trabalho pedagógico, as suas particularidades e especificidades.

O sexto e último período é denominado por Saviani (2009) "Advento dos Institutos de Educação e das Escolas Normais Superiores" (1996-2006).

Com o final do regime militar, o movimento de mobilização dos educadores no Brasil, alimentava a esperança de que o problema da formação docente seria equacionado com a nova LDB (9.394/96). Entretanto, a LDB não correspondeu às expectativas, uma vez que introduziu, como alternativa aos cursos de Pedagogia e de Licenciatura, os Institutos de nível superior de segunda categoria, provendo uma formação mais aligeirada e barata, por meio de cursos de curta duração. (SAVIANI, 2009). Por conseguinte, tais características foram contempladas nas novas diretrizes curriculares do curso de Pedagogia, homologadas em abril de 2006.

\section{A legislação e as políticas educacionais que regulamentam a formação docente anterior à LDB n. 9.394/96}

Gatti e Barreto (2009) informam que somente após 1960, é que se encontra a legislação orientadora da formação de professores no Brasil, com relação à estrutura curricular dos 
cursos de formação de professores. Nesse contexto, as Leis n. 4.024/61, 5.540/68, 5.692/71 e 7.044/82 estabeleceram normatizações em nível federal e estadual.

Como é sabido, com relação ao ensino primário (anos iniciais do ensino formal), a formação de professores se dava nas Escolas Normais de nível médio (secundário), desde as primeiras décadas do século XX. Por outro lado, a formação de professores para o curso secundário acontecia nas instituições de nível superior (licenciaturas).

A Educação Básica, no Brasil foi reformulada pela Lei 5.692/71, que extinguiu as escolas normais. A formação, por conseguinte, passa a ser feita em uma habilitação do ensino de segundo grau, denominada Magistério. Com a mudança, tal formação perdeu sua especificidade, uma vez que tinha que, ao mesmo tempo, ajustar seu currículo no ensino de Segundo Grau (médio) e dar formação de professor. Isso gerou um currículo disperso, tornando a parte da formação específica muito reduzida. Acredita-se que, dessa forma, ocorreu uma descaracterização dessa Habilitação no que se refere à formação para a docência.

Em 1982, o art. 30 da Lei 5.692/71 foi alterado pela Lei n. 7.044/82, que mantém a formação na Habilitação do Magistério, mas introduz outras opções formativas para os docentes dos anos iniciais e finais do Ensino Fundamental.

Em seguida, criaram-se os cursos de Licenciatura curta, em nível superior, com menos horas-aula do que as licenciaturas plenas. para formar docentes que poderiam atuar de $5^{\mathrm{a}}$ a $8^{\mathrm{a}}$. séries e também, de $1^{\mathrm{a}}$ a $4^{\mathrm{a}}$ séries.

O modelo de Licenciatura curta foi criticado, gerando polêmicas e contraposições de acadêmicos e entidades corporativas, o que levou o Conselho Federal de Educação (CFE), alguns anos depois, a emitir orientações de tornar progressivamente em plenas tais licenciaturas curtas. Elas só foram extintas completamente após a promulgação da nova LDB.

Ainda em 1982, o Governo interveio na questão da formação de professores e criou os Centros Específicos de Formação e Aperfeiçoamento do Magistério (Cefams), como já informado anteriormente. O objetivo foi atenuar os problemas detectados com relação às carências de formação docente. Segundo Pimenta (1995), os Cefams foram se expandindo em número e ofereciam cursos de formação integral, currículos voltados para a formação geral e pedagógica dos docentes, com ênfase nas práticas de ensino e, por isso, conseguiram melhorar a qualidade da formação oferecida.

Contudo, com a promulgação da Lei 9.394/96, nova LDB, esses centros, que proviam formação em nível médio, foram fechados e a formação docente foi transferida para o nível superior.

O Curso de Pedagogia foi reformulado em 1986, pelo Conselho Federal de Educação, que aprovou o Parecer n. 161, o qual delegou a esses cursos oferecer também a formação para a docência de $1^{\mathrm{a}}$. a $4^{\mathrm{a}}$ séries. Esse curso, de natureza sempre contraditória, tendo em vista seu histórico legal, já sofrera reformulações anteriores, a saber: Lei n. 5.540/68, da Reforma Universitária, configurada no parecer CFE N. 252/1969 e na Resolução n. 2/1969. Com essas prescrições, normatizou-se "[...] a formação do pedagogo com ênfase na formação do especialista, correspondendo ao modelo educacional tecnicista hegemônico no período, e mantém-se aí a formação do professor para as Escolas Normais em nível de segundo grau". (GATTI; BARRETTO, 2009, p. 41) . Além de poder dar aulas nas escolas normais, foi facultado ao pedagogo dar aulas também nas séries iniciais, como justifica Brzezinski:

[...] a estruturação do curso de pedagogia facilitou a adoção da premissa "quem pode o mais pode o menos", isto é, se os licenciados em Pedagogia 
estavam habilitados a formar professores de professores primários, por "osmose" adquiririam o domínio dos conteúdos do curso primário. (BRZEZINKSKI, 1996, p. 45)

Quanto ao currículo das licenciaturas em geral, as resoluções do CFE indicavam um currículo mínimo a ser cumprido em cada uma delas, definido por disciplinas obrigatórias. O desenho curricular dos cursos privilegiava a formação na área específica e a complementação pedagógica ficou somente no final do curso.

Estudos denunciaram os problemas da formação docente, no Brasil, nos períodos compreendidos entre 1950 e 1986. Assim, autores

[...] denunciam uma grande imprecisão sobre qual o perfil desejável a esse profissional, e que diferentes obras, ao longo do tempo, fazem críticas aos currículos dos cursos apontados como enciclopédicos, elitistas e idealistas. Consideram, ainda, que as diferentes reformas acabaram por aligeirá-los cada vez mais tornando-os, na sua maioria, currículos de formação geral diluída e formação específica cada vez mais superficial (SILVA et al., 1991, p. 135).

Daí percebe-se a identidade problemática do licenciado, entre duas formações estanques: especialista em área especifica ou professor, ou seja, Matemático ou professor de Matemática, Geógrafo ou professor de Geografia? Essas questões ainda se encontram em pauta, uma vez que não foram resolvidas até hoje. (GATTI, 1992, apud GATTI; BARRETTO, 2009).

Mediante tantas discussões e controvérsias relacionadas à formação docente, pesquisadores sobre o tema apontam as orientações dos documentos oficiais e literatura (ALVES, 1988; ANFOPE, 1992, etc) e alertam sobre a necessidade de revisão desses cursos:

- necessidades formativas diante da situação existente;

. formas de articulação e relação entre formação em disciplina específica, formação educacional geral e formação didática especifica, levando em conta os níveis de ensino;

. novas formas de organização institucional que possam dar suporte a essas necessidades e novas formas de articulação; formação dos formadores, ou seja, de pessoal adequadamente preparado para realizar a formação de professores no nível de $3^{\circ}$. Grau;

. novo conceito de profissionalização dos professores baseado na proposta de um continuum de formação. (GATTI; BARRETTO, 2009 p. 42)

Por conseguinte, em 1990 foi publicada a Declaração Mundial sobre educação para todos: plano de ação para satisfazer as necessidades básicas de aprendizagem, elaborada pela UNESCO. Silva Júnior apud Souza (2006, p. 2) criticou o conteúdo da Declaração, afirmando que a educação é considerada uma atividade formadora de um ser humano reificado e adaptável a qualquer pacto social; discutiu, ainda, a importância dada às parcerias com a sociedade civil, que remetem à mercantilização da educação.

Nesse mesmo sentido, Silva Júnior apud Souza (2006, p. 2) comentou sobre os dois documentos dos Governos Itamar e FHC: o Plano Decenal de Educação para Todos (1994), 
publicado com a UNESCO, e o Planejamento político-estratégico do MEC (1995-1998), considerado orientador das reformas educacionais. Tais documentos enfatizaram o papel da escola, havendo, segundo o autor, uma transferência de deveres do Estado para a sociedade civil, possibilitada pela municipalização da educação.

Deve-se reconhecer que, na década de 1980, emergiram pedagogias contra hegemônicas; porém, houve muitos obstáculos para viabilizar a "abertura democrática" no país, apresentando resultados pouco animadores. Vários municípios ${ }^{5}$ tentaram implantar políticas educativas "de esquerda", orientados por vertentes progressistas, com Governos de estado e municípios que assumiam a oposição contra o regime militar e a ditadura.

Na década de 1990, aconteceu a ascensão de Governos neoliberais, orientados pelo Consenso de Washington, que passaram a promover reformas educacionais caracterizadas pelo modelo do neoconservadorismo. SAVIANI (2007) explica que fora promovida uma reunião em 1989, por John Williamson, no International Institute for Economy, localizado em Washington, para discutir as reformas consideradas importantes na América Latina. Em 1990, foram publicados os resultados dessa reunião. Williamson denominou Consenso de Washington todo o

[...] o conjunto das recomendações saídas da reunião porque teria constatado que se tratava de pontos que gozavam de certa unanimidade, ou seja, as reformas sugeridas eram reclamadas pelos vários organismos internacionais e pelos intelectuais que atuavam nos diversos institutos de economia. (p. 425)

Ora, esses princípios refletem os rumos tomados pela política mundial após a ascensão de Margaret Thatcher, na Inglaterra, que governou ente 1979 e 1990, e de Ronald Reagan, nos Estados Unidos, cujo Governo se estendeu de 1981 a 1989. Esse novo pensamento hegemônico orientava o ataque ao estado regulador e a defesa do retorno do estado liberal, idealizado pelos clássicos.

Destarte, a orientação dentro dos preceitos do Neoliberalismo chega ao Brasil com força total, após a década de 1990, e a pesquisa de Borges (2009) revelou que, nessa perspectiva,

[...] o neoliberalismo de mercado julga o Estado falido e incompetente para gerir a educação; por isso, dá ênfase ao ensino privado, na busca da eficiência e qualidade de ensino. Propõe uma escola diferenciada e dualista, oferecendo o ensino propedêutico para a formação das elites intelectuais, e os cursos profissionalizantes para a classe menos favorecida, atendendo assim, as demandas do mercado de trabalho. (p.31)

Assim, a Lei de Diretrizes e Bases da Educação (LDB) 9.394/96 foi promulgada em meio a esse cenário de discussões, mudança de paradigmas, debates e proposições.

\section{A formação docente pós LDB (9.394/1996)}

Com a promulgação da nova Lei, surgiram muitas propostas sobre a formação de professores. Contudo, houve um período de transição e, por algum tempo, permaneceram as influências do período anterior. 
A partir de 2002, quando foram promulgadas as Diretrizes Curriculares Nacionais para a Formação de Professores (DCN), é que foram feitas as primeiras adaptações nos currículos de formação docente. Posteriormente, foram promulgadas também as diretrizes curriculares para cada curso de licenciatura, aprovadas pelo Conselho Nacional de Educação.

É importante destacar aqui a exigência de nível superior para os professores da educação básica, da LDB (9.394/96), expressa nos artigos 62 e 63:

Art. 62 - A formação de docentes para atuar na educação básica far-se-á em nível superior, em curso de licenciatura, de graduação plena, em Universidades e institutos superiores de educação, admitida como formação mínima para o exercício do magistério na educação infantil e nas quatro primeiras séries do Ensino Fundamental, a oferecida em nível médio, na modalidade Normal.

Art. 63 - Os Institutos Superiores de Educação manterão:

I - Cursos formadores de profissionais para a educação básica, inclusive o curso normal superior, destinado à formação de docentes para a educação infantil e para as primeiras séries do Ensino Fundamental;

II - Programas de formação pedagógica para portadores de diplomas de Educação Superior que queiram se dedicar à educação básica;

III - Programas de educação continuada para profissionais de educação dos diversos níveis.

Assim, foi concedida às Universidades a possibilidade de organização de cursos de formação de professores, de acordo com seus projetos institucionais, desde que fossem feitos em licenciaturas plena, com liberdade para incorporar ou não a figura dos Institutos Superiores de Educação (ISEs). Na análise de Gatti e Barreto (2009), os ISE's representaram, no âmbito das Faculdades isoladas ou integradas, o novo formato de formação docente, substituindo os cursos fragmentados existentes. Além disso, os ISE's ofereceram a possibilidade de integração, com base comum, na formação de professores para os diversos níveis de ensino e especialidades, institucionalizando a Escola Normal Superior no âmbito dos ISE's. (Art. 63).

Nessa época, a maioria dos professores do Ensino Fundamental, no Brasil, possuía formação de Ensino Médio, no curso de Magistério e, ainda, milhares de professores leigos. Nas disposições transitórias, a Lei fixou o prazo máximo de dez anos para que os sistemas de ensino se adequassem às novas normas.

Consequentemente, a superação da fragmentação dos currículos de formação passou a ser uma exigência legal. A preocupação em garantir maior articulação das diferentes modalidades formativas, ficou explícita na legislação. Assim, em 1999, o Conselho Nacional de Educação publicou a Resolução CP n. 1/99, que trouxe em seu artigo $1^{\circ}$, a nova proposta de estrutura formativa contida na $\mathrm{LDB}$ e, nos arts. $2^{\circ}$ e $3^{\circ}$, que propôs um caráter orgânico para seu funcionamento e flexibilidade de organização e denominação.

A Resolução trouxe também a preocupação com a qualidade do corpo docente para os ISEs, em seu art. $4^{\circ} \S 1^{\circ}$ e incisos; colocou exigências maiores com relação à formação dos formadores, exigindo uma porcentagem com qualificação em nível de mestrado, doutorado, dedicação exclusiva e comprovada experiência na educação básica.

Além disso, a resolução apontou a necessidade da participação coletiva dos docentes na elaboração e avaliação do Projeto Pedagógico dos Cursos. 
Nesse prisma, as proposições da LDB, reafirmadas na Resolução n. 1/99 do CNE, indicaram um novo momento nas perspectivas sobre a formação de professores, tanto na estrutura curricular, como na articulação formativa dos currículos e ainda na preocupação com a qualificação dos formadores de formadores, dos professores da Educação Básica. Além disso, para as Universidades, a formação científica sempre foi uma exigência, concretizada por meio das pesquisas propostas nos currículos de formação docente.

Entretanto, após essa Resolução, foram autorizados cursos de formação de professores isolados, em Escolas Normais Superiores, perdendo a organicidade de formação docente. As orientações das Diretrizes Nacionais para a formação de professores foram colocadas em segundo plano, criaram-se cursos de licenciaturas independentes, perdendo as articulações previstas. Assim,

A desagregação que as pesquisas evidenciam no que respeita à formação de professores e sua fragmentação interna em termos de currículo parece corresponder a interesses institucionais cristalizados, ou a falta de perspectivas quanto ao perfil formador do profissional professor, e a redução de custos. Além da estrutura integrada exigida aos ISEs, as condições definidas para a contratação de docentes especificamente para eles também podem ter concorrido, no âmbito das instituições privadas, em virtude de seu custo maior, para que a ideia de um centro específico formador de docentes, fosse um instituto ou uma faculdade, não vingasse. Para as instituições universitárias públicas, alterações estratégicas de currículo ou estrutura organizacional implicariam remanejamentos institucionais e de docentes, o que demandaria mudança da cultura formativa, de representações cristalizadas. (GATTI; BARRETTO, 2009, p. 46).

As Diretrizes Curriculares Nacionais para a Formação de Professores da Educação Básica foram instituídas em 2002, com preocupação maior no desenvolvimento de competências pessoais, sociais e profissionais dos professores. Suas orientações foram direcionadas para os professores que atuarão na educação básica, em diferentes níveis. Indicaram que a formação para o exercício profissional específico deve considerar, de um lado, a formação de competências necessárias à atuação profissional, como foco à formação oferecida e à prática esperada do futuro professor e, de outro, a pesquisa, com foco no ensino e na aprendizagem, para compreensão do processo de construção do conhecimento. Postularam ainda que as aprendizagens deverão ser orientadas pelo princípio da ação-reflexãoação, tendo a resolução de situações-problema como uma das estratégias didáticas privilegiadas. No artigo $6^{\circ}$, reafirmou a importância da cultura geral e profissional, conhecimento pedagógico e conhecimento advindo da experiência. (BRASIL. MEC/CNE, 2002).

As Diretrizes orientaram, ainda, que a "prática deverá estar presente desde o início do curso e permear toda a formação do professor", em qualquer especialidade (art. 12), e explicitaram: que "a flexibilidade necessária, de modo que cada instituição formadora construa projetos inovadores e próprios, integrando os eixos articuladores nelas mencionados” (art. 14). Apontaram, também, os seis eixos articuladores para a construção da matriz curricular dos cursos de licenciaturas, a saber: 1) os diferentes âmbitos de conhecimento profissional; 2) o da interação e da comunicação, bem como do desenvolvimento da autonomia intelectual e profissional; 3) o da relação entre disciplinaridade e interdisciplinaridade; 4) o da formação 
comum com a formação específica; 5) o dos conhecimentos a serem ensinados e dos conhecimentos filosóficos, educacionais e pedagógicos que fundamentam a ação educativa; 6) o das dimensões teóricas e praticas.

Na visão de Gatti e Barreto (2009), entende-se que essa Resolução é o guia básico para os cursos de formação de professores, devendo as demais diretrizes curriculares específicas de área tomá-la como referência. Entretanto, nota-se que, embora os projetos pedagógicos dos cursos formadores de professores adotem essa referência, nem sempre, na prática, concretizam-na em seus currículos. O que se vê nos currículos das licenciaturas diversas é um peso enorme de disciplinas fragmentadas em horas-aulas, com muito pouca integração com as disciplinas pedagógicas.

Há, nesse aspecto, uma orientação normativa de articulação dos cursos formadores com os sistemas e as escolas de educação básica, para propiciar a prática e a experiência com a vida escolar; porém, essa iniciativa ainda se faz tímida nas instituições formadoras.

\section{A Política Nacional de Formação de Professores (Decreto nº. 6.755/2009)}

A Política Nacional para a Formação de Profissionais do Magistério da Educação Básica foi instituída pelo Decreto presidencial $n^{\circ} .6 .755 / 2009$, dispondo sobre a atuação da CAPES (Coordenação de Aperfeiçoamento de Pessoal de Nível Superior) para o fomento a programas de formação inicial e continuada. A proposta foi "organizar em regime de colaboração entre União, os Estados, o Distrito Federal e os Municípios, a formação inicial e continuada dos profissionais do magistério para as redes publicas de educação básica" (art. $1^{\circ}$ ). Objetivou apoiar "a oferta e a expansão de cursos de formação inicial e continuada a profissionais do magistério pelas instituições públicas de Educação Superior". E pretendeu, ainda, equalizar nacionalmente as "oportunidades de formação inicial e continuada dos profissionais do magistério" (art. $3^{\circ}$, incisos II e III).

Outra inovação de tal política foi a orientação para a criação de Fóruns Estaduais Permanentes de Apoio à Formação docente, com representantes de várias instituições, para articular planos estratégicos a serem formulados em coparticipação, a partir de diagnósticos, assim como acompanhá-los e avaliá-los. Os secretários estaduais de Educação devem presidir esses fóruns em seus respectivos estados. O Ministério da Educação (MEC) terá a incumbência de aprovar o plano estratégico, apoiando as ações de formação por meio de concessão de bolsas de estudo e bolsas de pesquisa para professores, provendo auxílio a projetos relativos às ações propostas e aprovadas, como também dando apoio financeiro aos estados, Distrito Federal, municípios e instituições públicas para a implementação dos projetos.

O Decreto propôs, ainda, ações formativas, no sentido de prever a articulação entre as instituições de ensino superior e as redes de ensino da Educação Básica e a participação dos estudantes nas atividades de ensino da educação básica e a participação dos estudantes nas atividades de ensino-aprendizagem da escola pública, com projetos pedagógicos, fomentados pela Capes, que proponham a inovação nas matrizes curriculares e percursos formativos, bem como propostas de revisão da estrutura acadêmica e curricular dos cursos de licenciatura e pesquisa que impactem a formação de docentes (arts. 10 e 11).

Atualmente, a Capes subsidia o PIBID (Programa de Institucional de Iniciação à Docência), inicialmente nas Universidades públicas e que agora se estende para as privadas. Tal programa pretende, dentre vários objetivos, melhorar a qualidade dos cursos de formação 
docente, propiciando aos licenciandos a superação da dicotomia entre teoria e a prática, colocando-os em contato com as escolas de educação básica para a convivência e a experiência docente por maior tempo e com a possibilidade de vivências enriquecedoras para a formação em processo.

Como essa orientação é recente, percebe-se um movimento de ampliação nos cursos e recursos concernentes à formação docente. Entretanto, necessita-se de mais tempo e foco para se avaliá-la.

\section{Desafios e perspectivas para a implantação da formação de professores com qualidade}

Analisando criticamente as inovações na estrutura das instituições e currículos da formação de professores no Brasil, Gatti e Barretto (2009) ponderam que qualquer proposta de inovações esbarra na representação tradicional e nos interesses instituídos; o que dificulta repensar essa formação de modo mais integrado e em novas bases, bem como a implementação de formatos novos que trariam avanços qualitativos nos cursos de formação, com reflexos nos trabalhos pedagógicos desenvolvidos nas escolas, como ocorreu em vários países nos últimos anos, como exemplo de Cuba, Coreia e Irlanda.

Desse modo, as propostas contidas no Decreto Presidencial 6.755/2009, na visão de Gatti e Barretto (2009), buscaram responder a desafios apontados por décadas nas análises realizadas nos países, sobre o processo de formação de docentes, entre eles: conseguir articulação entre níveis de gestão e também entre a interinstituições, bem como dessas com as redes de ensino, escolas e outros espaços educativos não formais; dar organicidade à matriz curricular e processos formativos; repensar currículos e suas formas de implementação, revendo estruturas das instituições formadoras e dos cursos; estudar mais a fundo os próprios processos formativos em suas diversas modalidades. Em nossa visão, está se buscando um rompimento com estruturas tradicionais de formação, mobilizando os instituídos já cristalizados em direção a uma transformação nas ações formativas. Desse modo, a proposta, como tal, avança, embora aspectos burocráticos e financeiros incluídos na forma de realização possam criar obstáculos à agilidade de implementação (aspectos dos arts. $4^{\circ}, 5^{\circ}, 6^{\circ}, 8^{\circ}$ e 13 ).

Outro fator dificultador é a mentalidade e representações vigentes nas instituições e seus membros, que se acham impregnadas pela conformação que historicamente se instituiu entre nós quanto à formação de professores. Deve-se, também, considerar a tensão entre acadêmicos, tecnólogos e educadores, em que a questão do racionalismo e do enciclopedismo se opõe às intencionalidades e finalidades humanísticas.

Assim, acreditamos que a educação verdadeiramente inclusiva é aquela que, à esteira de Severino (2001), contribui com os recursos simbólicos do conhecimento para garantir a todos e todas a fruição dos bens sociais e o direito da participação político-social, mediados por direitos objetivos. Só dessa forma, a educação “[...] constrói a cidadania e legitima a inserção dos indivíduos na pólis”. (SEVERINO, 2001, p. 90, grifos do autor)

Ao analisar criticamente as políticas e as práticas do sistema educacional brasileiro, verificamos que as políticas educacionais atuais encontram-se orientadas pelos valores do neoliberalismo, que reafirmam os preceitos de uma sociedade capitalista, excludente e seletiva. Se, por um lado, apresentam discursos democráticos e includentes, defendendo a democratização do acesso à escola; por outro, organizam-se sistemas duais de ensino: uma 
escola propedêutica para a elite - que garante o acesso dos alunos ao conhecimento científico e, portanto, o alcance dos cursos de graduação mais concorridos e que assegurem maior status social; e uma escola técnico profissionalizante para a maioria que pertence à classe menos abastada, com possibilidade de acesso aos cursos de graduação de menor status social, dentre estes, os cursos de Licenciatura, que formam professores.

Diante do exposto, pode-se afirmar que a história da formação dos professores, nos últimos dois séculos, explicita sucessivas mudanças introduzidas no processo de formação docente, com um quadro de descontinuidade, embora sem rupturas. Com relação à questão pedagógica, que, no início, era ausente, o tema foi penetrando lentamente até ocupar posição central nos ensaios de reformas da década de 1930; está presente nas políticas e discussões atuais sobre formação de professores, sem encontrar, ainda, um encaminhamento satisfatório e coerente entre o conteúdo dos discursos e a sua efetivação prática. Por fím, na história brasileira, as políticas formativas evidenciam sucessivas mudanças, contudo ainda não estabeleceram um padrão minimamente consistente de preparação docente para resolver os problemas enfrentados pela educação escolar, principalmente com relação à qualidade do ensino.

No Governo Lula, houve um investimento na Educação Superior, por meios dos projetos de expansão universitária. A Universidade cresceu em número de vagas, oportunizando maior inclusão na Educação Superior. Contudo, ainda, a Universidade brasileira se depara com muitas dificuldades, iniciadas pela inserção histórica na sociedade capitalista. Os recursos são parcos e muita coisa ainda precisa de ser feita para que se alcance uma Universidade democrática e de qualidade, para todos que a desejarem.

Severino (2009) afirma que a Universidade enfrenta problemas no interior de sua esfera específica, como lugar de produção, sistematização e disseminação do conhecimento, problemas ainda não superados. Nesse prisma, persiste o desafio para a Universidade brasileira rever com "[...] criticidade, criatividade e competência, sua relação com o conhecimento, tratando-o como processo e não como produto, equacionando-o como mediação da educação e esta, como mediação da cidadania e da democracia" (SEVERINO, 2009, p. 254).

No tocante à Universidade que oferece os cursos de licenciatura e forma professores, para a formação docente realmente de qualidade - aquela que atenda às prementes necessidades, considerando o contexto social, econômico e político do Brasil muita coisa ainda precisa de ser revista. Dentre vários aspectos, elencam-se, aqui, alguns deles, considerados imprescindíveis:

- que a Nação assuma a educação realmente como prioridade, comprovada nos ricos e importantes investimentos realizados na formação inicial e continuada (cultura geral, específica na área de conhecimentos, profissionalizante e formação pedagógica - "Didática");

- que se dobre o valor do investimento do PIB (Produto Interno Bruto) na educação, para garantir a efetivação das políticas educacionais, para que sejam colocadas efetivamente em prática, ultrapassando o nível dos discursos políticos vazios existentes;

- que os currículos da formação docente possam subsidiar a abertura para a superação de paradigmas conservadores da modernidade, e possa adotar uma visão mais ampliada sobre a interdisciplinaridade, o trabalho em grupo, o processo de ensinagem ${ }^{6}$ na perspectiva da construção do conhecimento, a avaliação, a interdependência entre a teoria e a prática; tudo isso considerando o tripé ensino, pesquisa e extensão; 
- que os currículos dos cursos de formação de professores garantam a formação que contemple conteúdo, técnica (forma), formação pedagógica e, também, a formação política;

- que haja revisão dos investimentos na carreira do professor, com planos de carreira eficientes e garantia de salários dignos e valorização dos profissionais que se destacam na missão de ensinar;

- que o profissional docente tenha melhores condições de trabalho no cotidiano escolar: horas destinadas ao planejamento conjunto, ao estudo, à reflexão sobre a sua prática, à troca de experiências e à busca de estratégias e recursos inovadores;

- que se promova conscientização da sociedade como um todo, sobre o valor da educação para o país e, consequentemente, dos educadores que são os atores coadjuvantes desse processo.

Por fim, nota-se que a melhoria do processo de formação de professores carece de muito mais do que Leis e Decretos. É um grande desafio que exige muito investimento, tempo, colaboração de todos, mudança de mentalidade e comprometimento de toda a sociedade.

Destarte, o desânimo e o conformismo devem ser superados. Por isso, conclui-se à esteira de Gentili (1996), retomando a sentença gramsciana que aqui tem o sentido exato: $o$ pessimismo da inteligência, o otimismo da vontade. Deve-se usar o pessimismo da inteligência para compreender criticamente a ações e as consequências perniciosas e ofensivas da ideologia neoliberal em desfavor da formação de professores para a educação da maioria, que é a classe menos abastada. Porém, não se pode abrir mão do otimismo da vontade, o qual ajuda todos e todas a se manterem esperançosos e ativos perante os desafios e na luta contra o sistema de exclusão social, que enfraquece as bases de sustentação democrática, restringindo o direito à educação, que é como pré-requisito essencial para a conquista da cidadania. Crê-se, desse modo, que a cidadania completa que só pode ser efetivada numa sociedade igualitária, construída com o esforço conjunto, paciente, ativo e esperançoso de toda a sociedade. A mobilização e a força dos educadores têm importância fundamental para a missão de construir um sistema educacional de ensino superior, que realmente prepare e certifique professores, dotados de ampla e sólida formação, para, consequentemente, poderem contribuir com uma escola de educação básica, muito mais profícua, portanto, de boa qualidade e eficiente no processo de ensinagem.

\section{Referências:}

BORGES, M. C. Políticas Educacionais e a gestão democrática na escola pública de qualidade. São Paulo: Paulus, 2009.

BRASIL, Ministério da Educação. Lei 9.394/96. Lei de Diretrizes e Bases da Educação Nacional. Brasília: MEC, 1996.

BRASIL. Lei 5.692/71, de 11 de agosto de 1971. Diário Oficial da União, Brasília, 12 ago. 1971.Disponível em:< http://www.soleis.adv.br>/. Acesso em 24 jul. 2010.

BRASIL/MEC/CFE. Parecer 349/72. Documenta, n. 137, p. 155173, abr. 1972. . Disponível em : <www.soleis.adv.br>. Acesso em: 16 jul. 2010. 
BRASIL/MEC. Resolução CNE/CP 1, de 18 de fevereiro de 2002. Institui Diretrizes Curriculares Nacionais para a Formação de Professores da Educação Básica, em nível superior, curso de licenciatura, de graduação plena. Disponível em:

< http://portal.mec.gov.br/cne/arquivos/pdf/rcp01_02.pdf> Acesso: 20 dez. 2010.

BRASIL/MEC. Decreto n. 6.755, de 29 de janeiro de 2009. Institui a Política Nacional de Formação de Profissionais do Magistério da Educação Básica, disciplina de atuação da Coordenação de Aperfeiçoamento de Pessoal do Nível Superior - CAPES - no fomento à programas de formação inicial e continuada, e dá outras providências. Disponível em: <http://www.soleis.com.br/D6755.htm> Acesso em 20 dez. 2010.

BRZEZINSKI, I. Embates na definição das políticas de formação de professores para a atuação multidisciplinar nos anos iniciais do Ensino Fundamental para a atuação multidisciplinar nos anos iniciais do Ensino Fundamental: respeito à cidadania ou disputa pelo poder? Educação \& Sociedade, Campinas, v.20, n. 68, p. 80-108, 1996.

FREITAS, H.C.L. de. Formação de professores no Brasil: 10 anos de embate entre projetos de formação.2002. Disponivel em:< http://www.scielo.br/pdf/es/v23n80/12928.pdf> Acesso em: 30 set. 2010.

GADOTTI, M. História das Ideias Pedagógicas. 7. ed. São Paulo: Editora Ática, 1999.

GATTI, B. A.; BARRETTO, E. S. de S. (Coord). Professores do Brasil: impasses e desafios. Brasília: UNESCO, 2009.

GENTILI, P. (Org.) Neoliberalismo e educação: manual do usuário. In: SILVA, T. T.; GENTILI, P. Escola S. A. Quem ganha e quem perde no mercado educacional do neoliberalismo. Brasília, DF: CNTE, 1996.

LUCKESI, C. C. Tendências pedagógicas na prática escolar. In: . Filosofia da Educação. São Paulo: Cortez, 2005.

PIMENTA, S.G. O estágio na formação de professores: unidade entre teoria e prática. Cadernos de pesquisa, são Paulo, n. 94, p. 58-73, ago. 1995.

RIBEIRO JUNIOR, J. A formação Pedagógica do Professor de Direito. Campinas-SP: Papirus, 2001.

SAVIANI, D. Formação de professores: aspectos históricos do problema no contexto brasileiro. Rev. Bras. Educ. [online]. 2009. Vol.14, n. 40, pp. 143-155.

SAVIANI, D. Escola e Democracia. Teorias da Educação, curvatura da vara, onze teses sobre a educação política. 37. ed. Campinas, SP: Autores Associados, 2005. (Coleção Polêmicas do Nosso Tempo; v. 5).

SAVIANI, D. História das Ideias Pedagógicas no Brasil. Campinas,SP: Autores Associados, 2007.

SEVERINO, A. J. Educação, sujeito e história. São Paulo: Olho D’Água, 2001.

SEVERINO, A. J. Expansão do ensino superior: contextos, desafios e possibilidades. 2009. Disponível em: < http://www.scielo.br/pdf/aval/v14n2/a02v14n2>. Acesso em: 25 dez. 2009. 
SILVA, C. S. B. Curso de Pedagogia no Brasil: história e identidade. 2. Ed. Campinas: Autores Associados, 2003.

\author{
SILVA. A.N.; ESPOSITO, Y.L., SAMPAIO, M.M.; QUINTERIO, J. Formação de \\ professores no Brasil. São Paulo: FCC; REDUC, 1991.
}

SOUSA, M.L. de M. Mercantilismo na educação superior brasileira. Educ. Soc. vol.27 no.95 Campinas Mai/Ago. 2006 Disponível em: <http://www.scielo.br/scielo.php?script=sci_arttext\&pid=S0101-73302006000200015> Acesso dia 26 jul de 2010.

\title{
Notas:
}

1 É também conhecida como Escola Nova e localiza-se no Grupo das Pedagogias Liberais, teve como precursores Anísio Teixeira, Maria Montessori, dentre outros. Para saber mais sobre a Tendência liberal renovada Progressivista, leia LUCKESI, C. C. Tendências pedagógicas na prática escolar. In: Filosofia da Educação. São Paulo: Cortez, 1991.

${ }^{2}$ O termo darwinismo social é aqui utilizado como uma associação ao darwinismo de Darwin (1809-1882), cuja doutrina da evolução biológica é "fundada em dois princípios: 1. a existência das condições ambientais, e das quais algumas, pela lei da probabilidade, seriam biologicamente vantajosas; 2. a seleção natural graças à qual sobreviveram, na luta pela vida, os indivíduos em que se manifestassem as variações orgânicas mais favoráveis".(ABBAGNANO, 1962, p. 216). A seleção se dá, dessa forma, de maneira natural e vencem os melhores.

${ }^{3}$ A reforma universitária de 1968 aparece no bojo da formulação do projeto nacional-desenvolvimentista dos anos 50, que advogam um desenvolvimento autônomo e autossustentado, em que a problemática da ciência e tecnologia passou a integrar a agenda das políticas públicas. Abolição da cátedra e sua substituição pelo departamento, flexibilidade do ensino, integração da pesquisa nas atividades foram algumas das conquistas alcançadas na reforma universitária, mas os resultados modestos obtidos foram devidos ao desenvolvimento econômico acelerado, que induz à busca de "know-how" externo, em detrimento da tecnologia desenvolvida internamente e à falta de gestores para viabilização da política. NASCIMENTO, B.L.C REFORMA UNIVERSITÁRIA de 1968, origem do processo e resultados de uma política para o ensino superior. Tese (Doutorado em Educação) - Faculdade de Educação, Universidade Federal do Rio de Janeiro, 1991.

${ }^{4}$ Pedagogia Progressista Libertadora, idealizada por Paulo Freire, propõe uma relação horizontal entre alunos e professor, utiliza os temas geradores como conteúdo e a metodologia é a discussão em grupo dos problemas do contexto social dos educandos. Seu objetivo principal é levar os professores e alunos a atingirem um nível de consciência da realidade em que vivem, na busca de transformação social.

5 O Município de Uberaba-MG é um exemplo entre os que tentaram implantar políticas educativas "de esquerda", na gestão entre 1993-2000, a Secretaria de Educação Municipal abraçou a concepção pedagógica freireana, na busca de construir uma escola pública de educação básica, mais democrática e com maior qualidade no ensino. Mais informações em (DALBERIO, M.C.B. Escola Pública, Currículo e Educação emancipadora: o Projeto Político-Pedagógico como mediação. 2007. 239 p. Tese (Doutorado em Educação/Currículo). Faculdade de Educação. Pontifícia Universidade Católica de São Paulo. São Paulo, 2007.

6 Termo utilizado por Pimenta e Anastasiou, cujo significado indica que se há ensino tem que haver, consequentemente, a aprendizagem. Portanto, é a fusão dos dois termos: ensino e aprendizagem. Ver mais informações em PIMENTA, S. G.; ANASTASIOU, L. das G. C. Docência no ensino superior. São Paulo: Cortez, 2002. (Coleção Docência em Formação).

Recebido em: $\quad 04 / 01 / 11$

Aprovado em: 21/02/11 